\title{
¿FUE BAALBEK EL TEMPLO DE HELIOGÁBALO?: NUEVAS EVIDENCIAS
}

\author{
Was Baalbek the Temple of Heliogabalus?: New Evidences
}

\author{
Alberto GonZÁLEZ García \\ Universidad Complutense de Madrid \\ alberto.gonzalez.garcia@estumail.ucm.es
}

Fecha de recepción: $21-\mathrm{IV}-2012$

Fecha de aceptación: 25-IX-2012

Resumen: Hace algunos años, Warwick Ball propuso que el Templo de Elagabal de Emesa, jamás encontrado, debe identificarse con el complejo de templos de Baalbek. Más recientemente, Gary Young ha pretendido mostrar la endeblez de las evidencias con que apoyó tal aserto, así como la falsedad de algunas de sus suposiciones. Tratamos de refutar a Young y demostrar que las evidencias textuales, arqueológicas y epigráficas en realidad apoyan la tesis de Ball, añadiendo algunas nuevas pruebas.

Palabras clave: Baalbek, Emesa, Heliogábalo.

Авsтract: Some years ago, Warwick Ball suggested that Temple of Elagabal in Emesa, never found, it is to be identified with the temple complex at Baalbek. More recently, Gary Young intended to show the weakness of the evidence which he provided for this assertion, as well as the falseness on some assumptions. We try to refute Young and demonstrate that the textual, archaeological and epigraphic evidence actually supports Ball's theses, adding some new proofs.

Keywords: Baalbek, Emesa, Heliogabalus. 


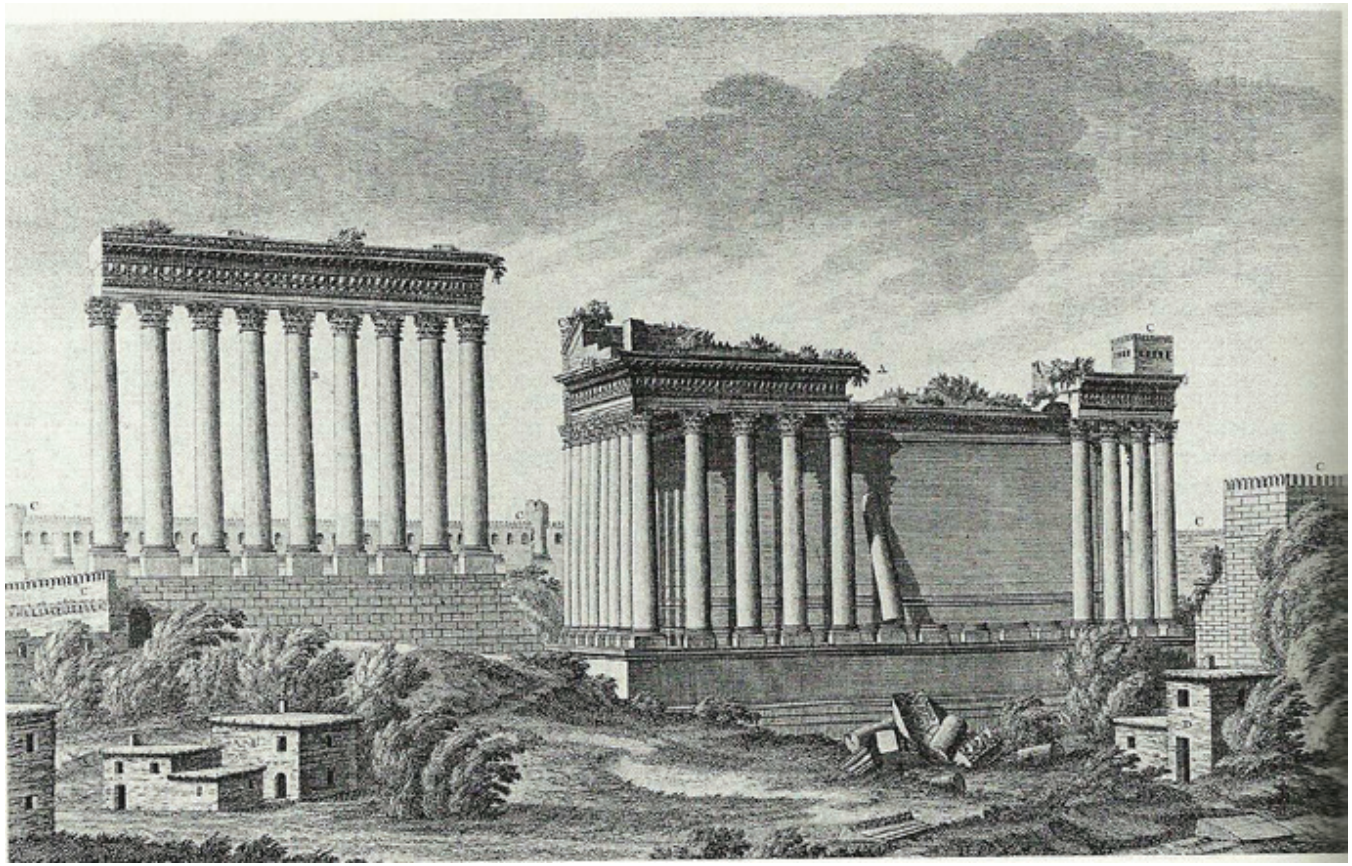

Fig. 1: Vista de la ruinas de Baalbek en el s. XVIII, WOOD, R. y DAWKINS, J. (1757): The ruins of Balbec, otherwise Heliopolis in Coelosyria, Londres, s/n, fig. 24.

\section{EL PROBLEMA DE BAALBEK Y LA TESIS DE BALL}

Durante siglos, el celebérrimo yacimiento arqueológico de Baalbek (fig. 1) ha constituido una verdadera pesadilla arqueológica debido a la falta de datos ${ }^{1}$. Según

MYERS, E.A. (2010): The Ituraeans and the Roman Near East. Reassessing the Sources, Cambridge, Cambridge University Press, 111-112. Sobre Baalbek, cf. PUCHSTEIN, O. (1905): Führer durch die Ruinen von Ba’albek, Berlín, Georg Reimer; WEIGAND, E. (1914): «Baalbek und Rom, Die römische Reichskunst in ihrer Entwicklung und Differenzierung», Jahrbuch des Deutschen Archäologischen Instituts 29, 37-91; WIEGAND, T. (1921-5): Baalbek: Ergebnisse der Ausgrabungen und Untersuchungen in den Jahren 1898 bis 1905, Berlín y Leipzig, W. de Gruyter; GERKAN, A. von (1937): «Die Entwicklung des grossen Tempels von Baalbek», en Curtius, L. (ed.), Corolla Ludwig Curtius zum 60. Geburtstag dargebracht, Stuttgart, W. Kohlhammer, 55-59; LYTTELTON, M. (1974): Baroque Architecture in Classical Antiquity, Londres, Cornell University Press, ; RAGETTE, R. (1980): Baalbek, Park Ridge, Noyes; BROWN, D.J. (1989): "The Hexagonal Court at Baalbek», AJA 43, 285-288; JIDEJIAN, N. (1998): Baalbek Heliopolis "Cité du Soleil», Beirut, Librairie Orientale; ESS, M. van, y WEBER, T. (coord; 1999): Baalbek, Im Bann römischer Monumentalarchitektur, Maguncia, Philipp von Zabern; FREYBERGER, K.S. (2000): «Im Licht des Sonnengottes: Deutung und Funktion des sogenannten 'Bacchus-Tempels' im Heiligtum des Jupiter Heliopolitanus in Baalbek», Damaszener Mitteilungen 12, 96-133; ESS, M. van ET AL.,(2003): "Archaeological Research in Baalbek. A preliminary report on the 2001-2003 seasons», BAAL 7: 109-144.; ESS, M. van, (2008): "Baalbek/Heliopolis. Results of Archaeological and Architectural Research 2002-2005», BAAL Hors-Sèrie 4, Beirut, Direction générale des Antiquités; ITO, J. y SUEYASU, S. (2009): «Reconstruction and Landscape Analysis of the Jupiter 
diversos estudios, el complejo religioso habría sido iniciado bajo los seléucidas, con una segunda fase constructora en época Julio-Claudia, la aún visible, que concluyó en el período entre Antonino Pío y Filipo el Árabe. Sin embargo, ningún emperador se atribuyó el mérito de edificar unos templos tan grandiosos que, aún hoy día, sus mezquinas ruinas cortan la respiración.

En el año 2000, el profesor Warwick Ball, antiguo director de la British School of Archaeology in Iraq, propuso la novedosa y audaz teoría de que Baalbek/Heliópolis se correspondería, en realidad, con el celebérrimo Templo de Heliogábalo, atribuido a la ciudad de Emesa (Homs). Este veterano excavador, uno de los mejores conocedores del Próximo Oriente antiguo, proponía doce argumentos difícilmente rebatibles ${ }^{2}$ :

1. No hay restos arqueológicos de importancia en Homs, ni en la gran mezquita de al-Nuri ni en la ciudadela. Lo cual resulta sumamente extraño, dada la fama y descripción del gigantesco templo, celebrado por su suntuosidad y riqueza. Sus homólogos hierosolimitano o damasceno, por citar los ejemplos más cercanos y famosos, sí que han dejado vestigios colosales perfectamente identificables hoy día.

2. Ninguna fuente menciona de forma clara y expresa que el templo que se encontrara en la propia ciudad: las referencias siempre son al Templo de los Emesenos, y no al templo de Emesa.

3. El santuario de Baalbek/Heliópolis, pese a ser uno de los mayores y más suntuosos del mundo romano, es casi completamente ignorado por las fuentes, al contrario que el de Baal Emeseno, que interviene de forma destacada en la historia romana con la expansión del culto de Elagabal, el ascenso al poder de la dinastía severiana en general y del emperador Heliogábalo en concreto.

4. No hay evidencias claras sobre los dioses adorados en Baalbek, ni a quien se puede adjudicar cada uno de los cinco templos hallados hasta la fecha. Diversas investigaciones hablan de la tríada formada Baal-Júpiter, Astarté-Venus y Simius-Mercurio ${ }^{3}$, pero también hay pruebas de culto a las

Sanctuary at Baalbek Using 3D CG», en XXII CIPA Symposium - Kyoto, JAPAN - 11 October - 15 October 2009 (recurso electrónico: <http://cipa.icomos.org/fileadmin/template/doc/KYOTO/108.pdf> [Consultado el 20-04-2012]).

2 BALL, W. (2000): Rome in the East. The Transformation of an Empire, Routledge, Londres y Nueva York, 37-47.

3 Cf. WINNEFELD, H. (1914): "Zur Geschichte des syrischen Heliopolis», Rheinisches Museum für Philologie 69, 139-159; SEYRIG, H. (1929): «La triade héliopolitaine et les temples de Baalbek», Syria 10-4, 314-356; HAJJAR, Y. (1977): La triade d'Heliopolis-Baalbek, Leiden, Brill; KROPP, A.J.M. (2009): "The cults of Ituraean Heliopolis (Baalbek)», Journal of Roman Archaeolo- 


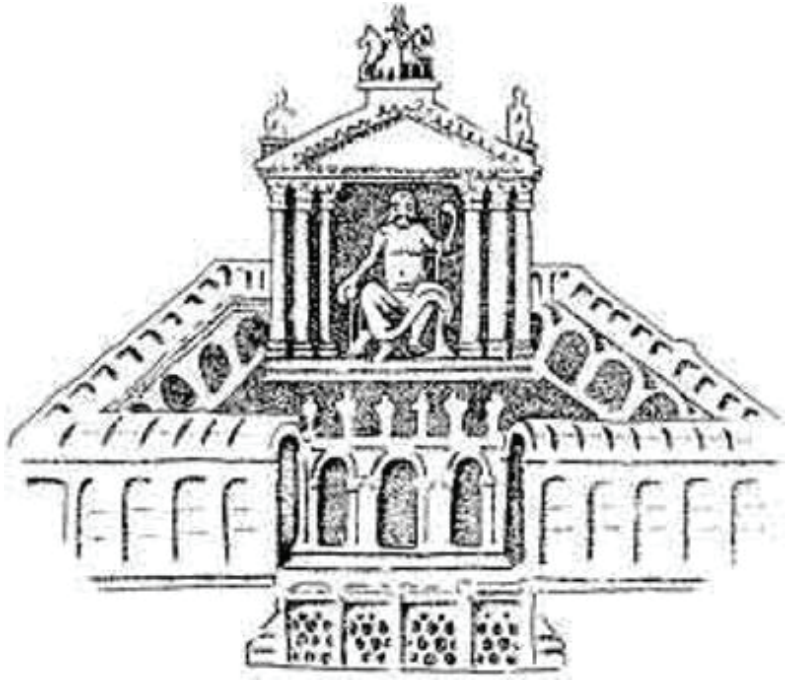

Fig. 2: el Elagabalium de Roma, según un medallón de Alejandro Severo, BALL, W. (2000): Rome in the East..., p. 47.

Musas, a Tyché y a Sabazio, un oscuro dios frigio-tracio. Lo evidente es que se trataba de cultos de origen oriental, y no romanos ${ }^{4}$. Lo cual, desde luego, no encaja con la teoría que convierte el templo en un foco de romanización promovido por las autoridades imperiales.

5. Las formas arquitectónicas de Baalbek son totalmente próximorientales, no romanas 5 . Su altar principal es idéntico a las representaciones del altar de Baal Emeseno, y el único parecido hallado hasta la fecha en todo el Oriente romano. Su patio, con dedicatorias de distintas ciudades, se corresponde con la mención que hace Herodiano del Heliogabalium, según la cual recibía generosos regalos de sus vecinos.

6. El Templo de Heliogábalo en Roma copia fielmente el modelo de Baalbek, con un templo sobre podio y una gran explanada precedida por un propileo (fig. 2).

7. El templo de Baalbek es el único en el cual sabemos positivamente que se rendía culto a una piedra cónica, como ocurría en el Templo de los Emesenos.

8. Existe en Baalbek una inscripción honrando a «Sohemo, hijo de Samsigeramo»,

gy 22, 365-80; KROPP, A.J.M. (2010): «Jupiter, Venus and Mercury of Heliopolis (Baalbek). The Images of the "Triad» and Its Alleged Syncretisms», Syria 87, 229-65.

4 TURCAN, R. (1996): The Cults of the Roman Empire, Oxford, Blackwell, 315-325.

5 Algo confirmado por MYERS, E.A. (2010): The Ituraeans and the Roman Near East..., 99, que, sin embargo, atribuye un origen itureo al complejo. 
gran rey de los emesenos (54-73 d. C.), como patrón de la colonia. Ningún emperador, en cambio, se atribuyó el considerable mérito de su edificación.

9. La situación de la ciudad de Baalbek en el territorio de Beirut no implica, per se, que el santuario no pudiera pertenecer a los emesenos, ya que tales solapamientos eran comunes en el Oriente romano. Podríamos ańadir, de nuestra propia cosecha, la idea de que jurisdicción no es lo mismo que propiedad.

10. Donaciones aparte, una ciudad menor como Baalbek, una localidad sin importancia comercial, en un valle que evitaban las principales rutas comerciales de la zona, carecía de recursos con los que construir templos tan gigantescos y suntuosos, al igual que los reyes itureos de Calcis. En cambio, todo lo contrario era el caso de los opulentos reyes emesenos.

11. Fue Septimio Severo, emparentado con la familia real de Emesa, quien elevó a Baalbek a la condición de Colonia Iulia Augusta Felix Heliopolis, con Ius Italicum, en tanto que Caracalla hizo lo propio con Emesa, elevándola además a la categoría de capital de la Phoenicia Libanensis ${ }^{6}$. El vínculo con los Severos es persistente: la emesena Julia Domna, esposa de Septimio Severo, y su hijo Caracalla figuran en inscripciones de Baalbek $^{7}$, y la Tríada Heliopolitana aparece también en monedas acuñadas en la localidad natal de Alejandro Severo, Arca Caesarea ${ }^{8}$. La imagen de Júpiter Heliopolitano, entre dos toros y sobre dos victorias aladas, destaca en la coraza de la estatua de este último emperador hallada en Carnuntum. Aunque Ball no explicite el detalle, sabemos que Carnuntum - centro de la revuelta de Severo, que la convirtió en colonia- era cuartel de la Legio XIIII Gemina Martia Victrix, que en algún momento entre finales del siglo II y el primer tercio del siglo III estuvo destacada en Apamea, localidad natal del padre de Heliogábalo?. Desde luego, sería

6 ULPIANO, de Censibus, 9 (Digesto 50, 15, 1-2) y JUAN MALALAS XII, 26. El estudio numismático de SAWAYA, Z. (2009): Histoire de Bérytos et d'Héliopolis d'après leurs monnaies, Ier siècle av.J.-C.- IIIe siècle apr. J.-C., Beirut, IFPO, confirma que Baalbek perteneció a Beirut hasta 194.

7 CIL III, 138 = ILS 428: [I O M H V] M(ercurio) DIIS HELIVPOL(itanis), PRO SALUT[e / et] VICTORIIS D(omini) N(ostri) ANTONINI PII FEL(ici) AVG(usti) / ET IVLIAE AVG(ustae) MATRIS D(omini) N(ostri) CASTR(orum) SENAT(us) PAT(riae) / AVR(elius) ANT(onius) LONGINUS SPECVL(ator) LEG(ionis) I / [An]TONINIANAE CAPITA COLUMNARUM DVA AEREA AURO INLVMINATA SVA PECUNIA EX VOTO L(ibens) A(nimo) S(olvit)

8 HA Vit. Alex. Sev. 1, 2; AURELIO VÍCTOR, Caess. 24, 1; HAJJAR, Y. (1977): La triade d'Heliopolis-Baalbek, 247.

9 Cf. HAJJAR, Y. (1977): La triade d'Heliopolis-Baalbek, 325-334 y 349-50; KANDLER, M., y ZABEHLICKY, H. (1981): "Grebungen in einem Kulbezirk orientalischer Gottheiten in den Canabae legionis von Carnuntum im Jahre 1981», PAR 31, 29-32; ERTEL, C. (1991): «Der 

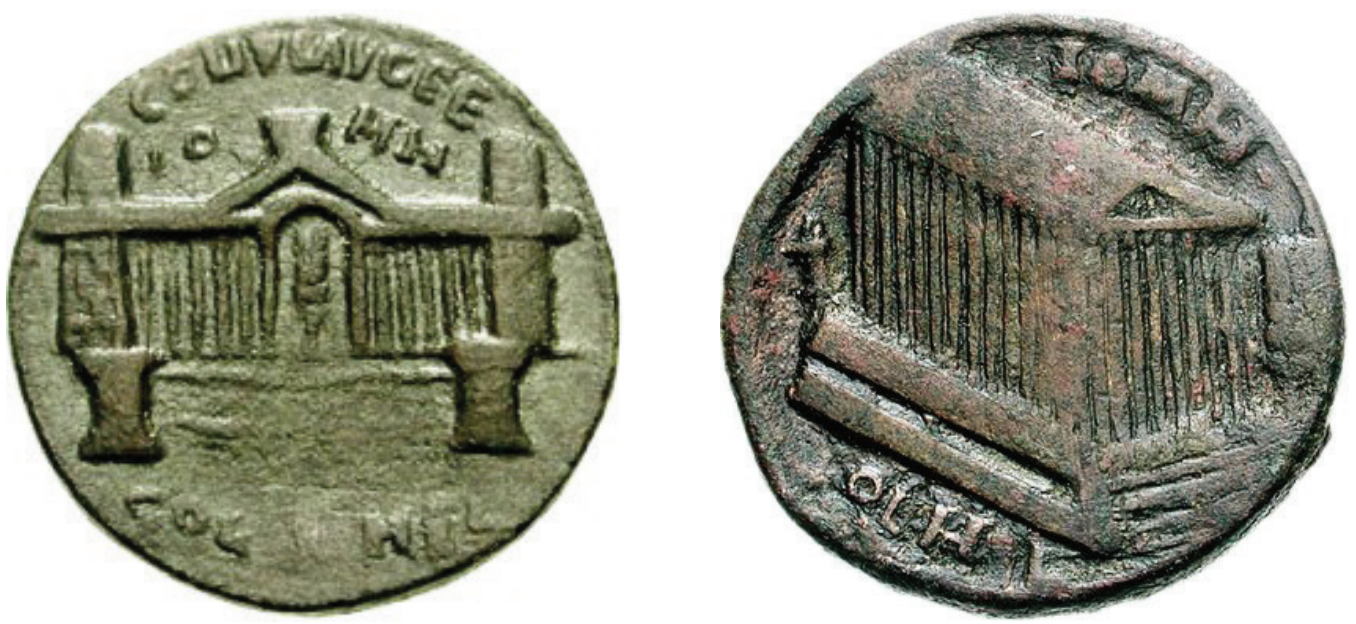

Figs. 3 y 4: Monedas heliopolitanas de Otacilia Severa (244-9), con el propileo del complejo, y el Gran Templo. Fuente: <http://wildwinds.com/coins/ric/otacilia_severa/_heliopolis_AE27_ BMC_23.jpg> y <http://coinproject.com/siteimages/97-76001109.jpg> [Consultados el 2004-2012].

cuanto menos singular que en una imagen dedicada a un emperador paisano suyo figurara un dios vecino en vez del propio. Bajo Septimio Severo, una cohorte vecina de arqueros emesenos, destacada en Intercissa (Dunaújváros), edificó un templo dedicado al Deus Sol Elagabalus, y poco después un monumento conmemorativo de las victorias de Caracalla en Germania, que invocaba a la misma deidad ${ }^{10}$.

12. Las monedas de los emperadores severianos, ligados a Emesa, y las de Filipo el Árabe y su esposa Otacilia (figs. 3 y 4), son las únicas que muestran el complejo de Baalbek. De igual modo, sólo Heliogábalo y Uranio Antonino muestran el templo de los emesenos.

Tempel A im Kultbezirk der orientalischen Götter in den Canabae legionis von Carnuntum», en MAXFIELD, V.A., y DOBSON, M.J. (eds.), Roman Frontier Studies 1989, Proceedings of the XVth International Congress of Roman Frontier Studies Canterbury 1989, Exeter, University of Exeter Press, 216-218; JOBST, H. (1998): "The cult of the oriental deities in Carnuntum», en FITZ, J. (ed.), Religions and Cults in Pannonia. Exhibition at Székesfehérvár, Csók lstván Gallery 15 May-30 September 1996, Székesfehérvár, István Király Múzeum, 37-42; GASSNER, V. (2003): "Heiligtümer sogenannter orientalischer Kulte in Carnuntum. Stadt und Landschaft der Antike», Andros Suppl. 3, 135-151; GASSNER, V. (2004): «Der Tempelbezirk des Iuppiter Heliopolitanus in Carnuntum - ein «syrisches» oder ein "pannonisches» Heiligtum?», en SCHMIDT-COLINET, A. (ed.), Lokale Identitäten in Randgebieten des römischen Reiches. Akten des Internationalen Symposiums in Wiener Neustadt, 2003, Viena, Phoibos, 239-257.

10 HALSBERGHE, G.H. (1972): The Cult of Sol Invictus, Leiden, Brill, 50-52; FITZ, J. (1982): The Great Age of Pannonia (AD 193-284), Budapest, Corvina, 11-13. 

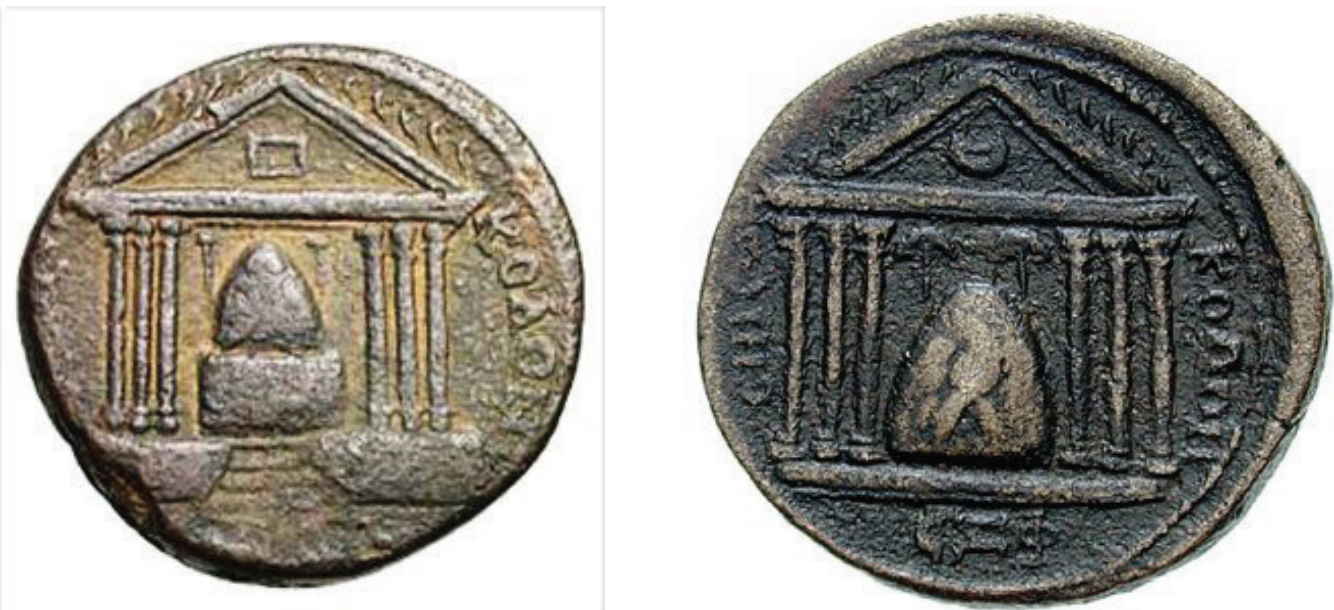

Figs. 5 y 6: monedas emesenas de Caracalla (215-6) y Uranio Antonino (253-4). Fuente: <http://www.wildwinds.com/coins/ric/caracalla/_emesa_BMC_15.jpg > y <http://commons. wikimedia.org/wiki/File:Bronze-Uranius_Antoninus-Elagabal_stone-SGI_4414.jpg> [Consultados el 20-04-2012]. Cf. BALDUS, H.R. (1971): Uranius Antoninus, Münzprägung und Geschichte, Bonn, Habelt, 250, nos. 38-42 (lám 4).

Ball aprecia que existen diferencias en la representación numismática que cuestionan su teoría: tal como aparece en las monedas, el Templo de Elagabal es períptero, de estilo corintio, con $6 \times 11$ columnas, sobre un podio con una escalinata, en tanto que el Gran Templo de Baalbek, aun siendo idéntico, presenta $10 \mathrm{x}$ 19 columnas. Su argumento es que las monedas no son representaciones ni planos exactos. Las cuatro columnas centrales podían omitirse para permitir ver la Piedra de Elagabal.

Podemos desarrollar este hecho añadiendo la comparación con la representación numismática de otros grandes monumentos coetáneos; así por ejemplo, el Coliseo no es tal cual figuraba en las monedas de Tito, donde el número de arcos es sensiblemente inferior. Lo mismo ocurre con la Basílica Ulpia en las de Trajano. Plasmar tantas columnas era complicado con los medios de la época, y el resultado en exceso abigarrado.

En efecto, en monedas de Severo y Caracalla, el templo de Heliópolis es representado correctamente como decástilo (figs. 9 y 10). Pero en una moneda emesena de Caracalla (fig. 11), el Templo de Heliogábalo, hexástilo en las demás monedas, parece tener 4 x 9 columnas. En otra tipología de piezas, emitidas bajo Filipo el Árabe, la representación de Baalbek es de todo menos realista (fig. 12). 

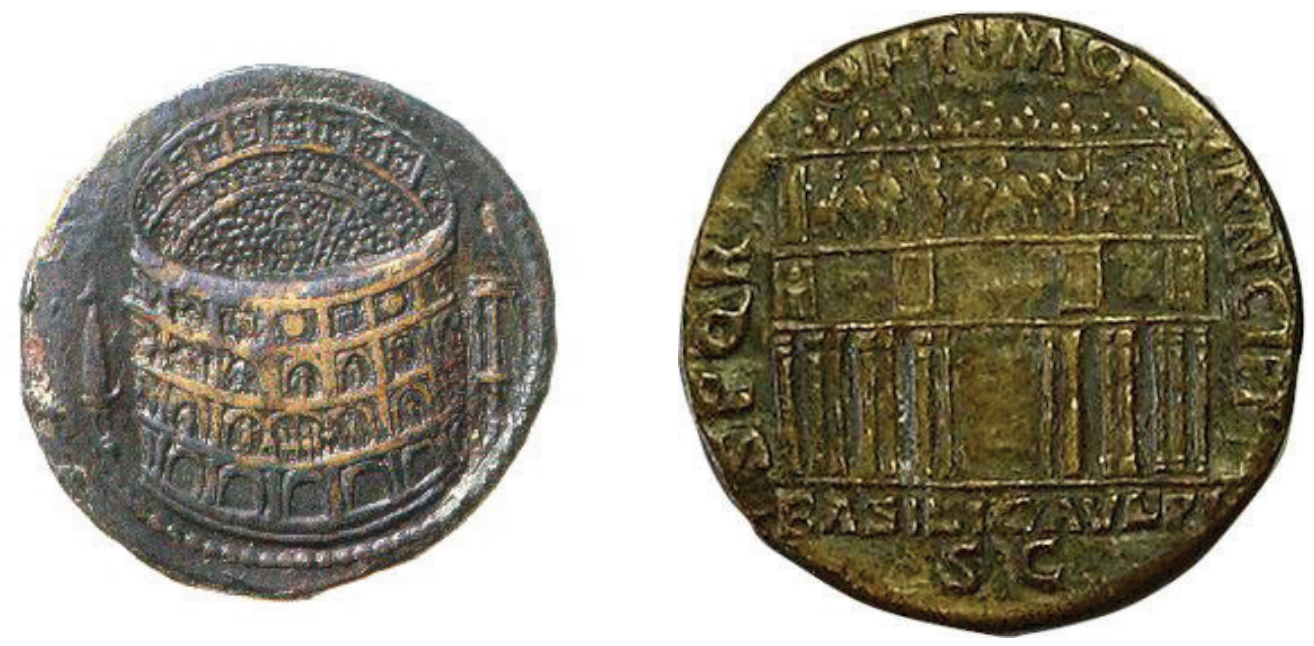

Figs. 7 y 8: monedas de Tito y Trajano. Fuente: <http://www.arch.mcgill.ca/prof/sijpkes/ abc-structures-2005/Lectures-2005/lecture-5/coin_tito80_col.jpg> y <http://www.stuartleeming.net/ROMEWEB/images/trajan/tb-coin.jpg> [Consultados el 20-04-2012].
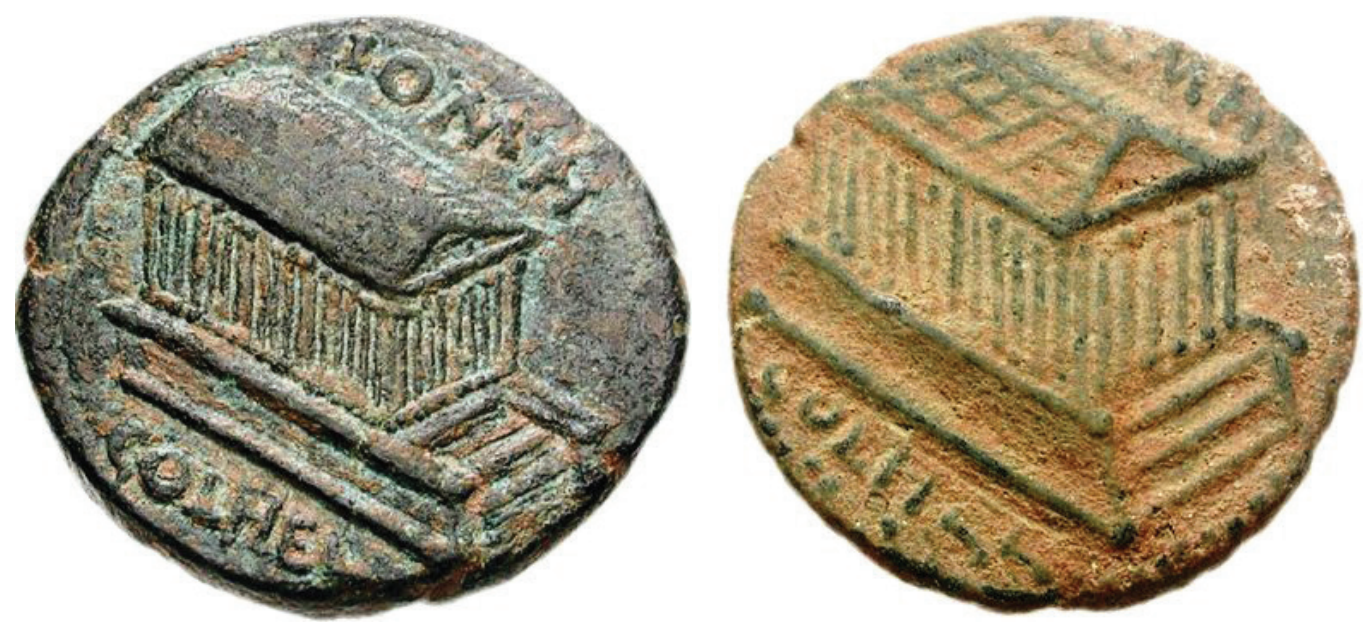

Figs. 9 y 10: monedas heliopolitanas de Severo y Caracalla. Fuente: <http://coinproject. com/siteimages/97-74000664.jpg> y <http://coinproject.com/siteimages/97-82000865.jpg> [Consultados el 20-04-2012]. 

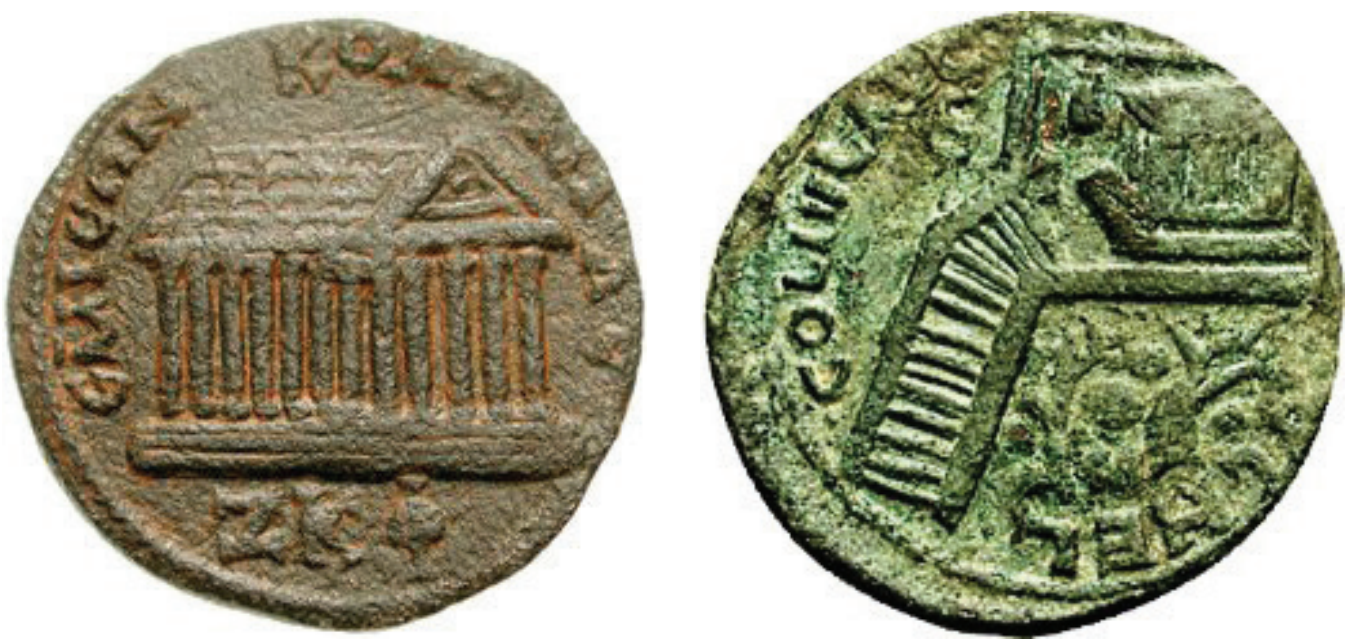

Figs. 11 y 12: moneda emesena de Caracalla y heliopolitana de Filipo el Árabe. Fuente: <http://coinproject.com/siteimages/97-150730.jpg> y <http://wildwinds.com/coins/ric/ philip_I/_heliopolis_AE28_SNGCop_435.jpg> [Consultados el 20-04-2012].

\section{LA CRÍTICA DE YOUNG}

En 2003, Gary Young, de la Universidad de Monash, publicó una crítica de la teoría de Ball, concluyendo que debe ser rechazada, por atractiva que pueda resultar ${ }^{11}$. Para Young, Heliópolis/Baalbek no estaba en territorio de Emesa y no hay pruebas que permitan identificar más allá de toda duda a Júpiter Heliopolitano con Heliogábalo, lo cual es cierto, pero no derriba la hipótesis de Ball. Su principal argumento es que dos fuentes demuestran sin duda alguna que el Templo de Heliogábalo se encontraba en la propia ciudad de Emesa:

1. Primero, el testimonio de Herodiano, según el cual soldados acantonados en Raphanaea (sede de la III Gallica) peregrinaban al templo y la ciudad de Emesa para ver a su sumo sacerdote, Heliogábalo.

2. Segundo, la Historia Augusta documenta que Aureliano visitó el Templo de Baal en Emesa tras su victoria sobre los palmirenos en 272.

Sin embargo, sus argumentos no resisten un análisis cuidadoso:

1. El testimonio de Herodiano no prueba en absoluto que el Elagabalium se hallara en la propia Emesa. Según la Historia Augusta, tras el asesinato de Antonino

11 YOUNG, G.K. (2003): «Emesa and Baalbek: Where is the Temple of Elahagabal?», Levant 35, 159-62. 
Caracalla en Carrhae, Heliogábalo huyó al templo de ese dios, para evitar la muerte a manos de los sicarios de Macrino, haciéndose célebre entre los soldados que lo visi$\operatorname{taban}^{12}$, lo que confirma el testimonio de Herodiano. Pero, si ya residía en Emesa, presunta localización del templo, ¿qué necesidad tenía de huir? Es interesante observar que el propio Herodiano no menciona el «templo de la ciudad», «la ciudad y su templo» o una fórmula semejante, sino que lo hace de forma separada: el templo por un lado $y$ la ciudad de Emesa por otro ${ }^{13}$. El orden también es relevante: primero la ciudad, y luego el templo. En efecto, los soldados que viajaran desde Raphanea se encontrarían primero con Emesa, y luego con Baalbek. Se conservan un par de inscripciones de un soldado de la III Gallica, Antonio Aurelio Longino, en Heliopolis/ Baalbek, datadas precisamente en esos años $(212-217)^{14}$, pero ninguna en Emesa. Ya en el período Flavio (69 d. C.), los soldados de la III Gallica saludaban al sol naciente siguiendo la costumbre local ${ }^{15}$, lo cual es indicativo de la preeminencia del culto solar heliopolitano. Por la misma época, Plinio se refería a Baalbek/Helipolis como Solis Oppidum ${ }^{16}$.

2. En realidad, lo que afirma la Historia Augusta es que Aureliano venció a las tropas de Zenobia cerca de Emesa, entró triunfal en la ciudad, y de inmediato ( ac statim») se encaminó («tetendit») al Templo de Heliogábalo ${ }^{17}$ :

Pugnatum est post haec de summa rerum contra Zenobiam et Zabam eius socium apud Emesam magno certamine. Cumque Aureliani equites fatigati iam paene discederent ac terga darent, subito vi numinis, quod postea est proditum, hortante quadam divina forma per pedites etiam equites restituti sunt. fugata est Zenobia cum Zaba, et plenissime parta victoria. Recepto igitur orientis statu Emesam victori Aurelianus ingressus est ac statim ad Templum Heliogabali tetendit, quasi communi officio vota soluturus.

Ball aducía que existían dos templos, uno menor en la propia Emesa, que fue el que visitó Aureliano, y un templo principal en Baalbek ${ }^{18}$. Y, en todo caso, considera que el templo de Emesa era mucho más reciente que el de Baalbek, pues Juan

12 HA Vit. Hel. 2, 3: "Hic fertur occiso Macrini factione patre, ut dicebatur, Antonino in templum dei Heliogabali confugisse, velut in asylum, ne interficeretur a Macrino, qui saevissime cum filio luxurioso et crudeli exercuit imperium»; HA Vit. Macr. 9, 3; AURELIO VÍCTOR, Caess. 23, 1. HERODIANO V, 3, 9.

14 IGLS 2711 y 2712.

15 TÁCITO III, 24, 6: "Undique clamor, et orientem solem, ita in Syria mos est, tertiani salutauere».

16 PLINIO, NHV, 18.

17 HA Vit. Aur. 25, 2-4.

18 BALL, W. (2000): Rome in the East..., 37-8. 
Malalas, indicaba que Galieno, devoto de Sol Invictus construyó un gran templo en Emesa ${ }^{19}$.

Pero lo cierto es que ni siquiera hace falta recurrir a este argumento (por lo demás, corroborado por las fuentes). Del texto no se desprende en modo alguno que el templo visitado por Aureliano se situara en el interior de la ciudad. La secuencia es clara: Aureliano derrotó a los palmirenos, entró triunfal en Emesa y, sin detenerse, se fue al templo para cumplir sus votos. Éste podía estar, o no, en la ciudad, y el empleo del verbo tendere, con sentido de encaminarse hacia un lugar distinto ${ }^{20}$, apunta más bien a que no. También apoya esta interpretación la utilización de la designación "Templum Heliogabali», en vez de limitarse a decir, «el templo de la ciudad».

Después de atribuir su victoria militar a Elagabal y de visitar el templo de los emesenos, en 273, Aureliano comenzó la emisión de moneda con la imagen de Sol Invictus, así como la construcción del fastuoso templo de este dios en el Campo Marcio ${ }^{21}$. Según la Historia Augusta, Aureliano fue hijo de una sacerdotisa del Sol, culto muy extendido en el ejército. Pero el caso es que parece haber nacido en Sirmio, a $300 \mathrm{~km}$ de Intercissa, donde se hallaba la cohors militaria Antoninana, reclutada entre emesenos, que, como ya hemos mencionado, construyeron un templo a Elagabal (vide supra). Su culto estaba extremadamente extendido por Panonia y la vecina $\mathrm{Dacia}^{22}$.

Como vemos, ninguno de los argumentos de Young logra rebatir en modo alguno la tesis de Ball.

Sobre la existencia de dos templos, uno en Heliópolis/Baalbek y otro en Emesa, Herodiano constata que Heliogábalo erigió no uno, sino dos templos en Roma ${ }^{23}$ : el bien documentado Elagabalium del Palatino ${ }^{24}$, y otro en las inmediaciones de la Urbe, que no ha sido localizado. La Historia Augusta confirma la edificación de un templo en el

19 JUAN MALALAS XII, 27.

20 GLARE, P.G.W. (ed., 1968): Oxford Latin Dictionary, Oxford, Oxford University Press, 1917-8.

21 HA Vit. Aur. 1, 3; 4, 2-5; 5, 5; 14, 3; 25, 4-6; 28, 5; AURELIO VÍCTOR, Caess. 35, 7; ZÓSIMO I, 61; cf. PLATNER, S.B., y ASHBY, T. (1929): A Topographical Dictionary of Ancient Rome, Oxford, Oxford University Press, 491-493; HALSBERGHE, K.H. (1972): The Cult of Sol Inivctus, Leiden, Brill, 136-171; RICHARD, J.C. (1976): "Le culte de Sol et les Aurelii. A propos de Paul Fest. p. 22 L.», en Mélanges offerts à Jacques Heurgon. L'Italie préromaine et la Rome républicaine, Roma, École Française de Rome, 915-925; WATSON, A. (1999): Aurelian and the Third Century, Londres y Nueva York, Routledge, 188-198.

22 HALSBERGHE, G.H. (1972): The Cult of Sol Invictus, 47-8 y 130-71.

23 HERODIANO V, 6, 6.

24 Cf. NASH, E. (1961): Bildlexicon zur Topographie des antiken Rom l, Tubinga, Deutsches Archäologisches Institut, 537 ss, figs. 663-670; BROISE, H., THÉBERT, Y. (1999): «Élagabal et le complexe religieux de la Vigna Barberini», Mélanges de l'Ecole française de Rome. Antiquité 111-2, 729747. En relación con este Elagabalium, el Antiquario Palatino conserva un relieve que muestra a la Tríada Heliopolitana, $c f$. HAJJAR, Y. (1977): La triade d'Heliopolis-Baalbek, 380-383. 
lugar del santuario de Orcus ${ }^{25}$. Orcus era una deidad rural, que no tenía culto oficial en las ciudades ${ }^{26}$, de modo que sería lógico suponer que este segundo templo se hallaba extramuros de Roma, y que, por tanto, bien podía replicar la relación existente entre Emesa y Baalbek. Otros autores creen que el santuario de Orcus se correspondía al templo del Palatino, y que el segundo santuario se situaba en el suburbio Ad Spem Veterem, en el Esquilino ${ }^{27}$, junto al Circo Variano y el Anfiteatro Castrense, en los llamados Horti Variani, propiedad del padre de Heliogábalo ${ }^{28}$. El relato de Herodiano parecer confirmar la aparente asociación del templo con los espectáculos circenses de este complejo. $\mathrm{Y}$ es interesante observar, en este sentido, que en el mal llamado "Templo de Baco» de Heliópolis/Baalbek también se conserva una inscripción circense, impetrando a la Tyche local la victoria para los Azules ${ }^{29}$. Lo que está fuera de toda duda es que uno de los dos templos se ubicaba fuera de la ciudad.

Según el relato de Herodiano, la piedra sagrada era trasladada de un templo a otro cada verano, lo cual es constatado por monedas de Heliogábalo, donde se ve la ve sobre un carro ${ }^{30}$. La existencia de una migración similar en Emesa es atestiguada por las monedas de Uranio Antonino ${ }^{31}$. Baalbek y Emesa están separadas por 90 millas romanas, unos $130 \mathrm{~km}$ de distancia, una ruta sencilla de cuatro días siguiendo el plácido curso del Orontes: la Tabula Peutingeriana muestra cuatro etapas entre «Eliopolis» y "Hemesa»: 20 millas entre Heliópolis y Heldo, 28 entre ésta y Fl. Elevter, 22 hasta Lavdicia Scabiosa, y otras 20 hasta Emesa ${ }^{32}$. De modo que la peregrinación entre ambas localidades sería perfectamente factible.

Con respecto a la epigrafía, Ball menciona la existencia de una inscripción en Baalbek que honra la memoria del rey-cliente emeseno Cayo Julio Sohemo (54-73). Sin embargo, no desarrolla en extensión su importancia. La inscripción, en el pedestal de una perdida estatua de bronce, es la siguiente ${ }^{33}$ :

25 Vit. Hel. 1, 6: «Et hic quidem prius dictus est Varius, post Heliogabalus a sacerdotio dei Heliogabali, cui templum Romae in eo loco constituit in quo prius aedes Orci fuit, quem e Syria secum advexit».

26 BERNHEIMER, R. (1952). Wild Men in the Middle Ages, Nueva York, Octagon, 43.

27 STUART HAY, J. (1911): The Amazing Emperor Heliogabalus, Londres, Macmillan, 105-6.

28 Vit. Hel. 13, 5 y 14, 5, cf. COLINI, A.M. (1955): "Horti Spei Veteris. Palatium Sessorianum», Memorie della Pontificia Accademia 7, 137-177.

29 IGLS 2836.

30 MATTINGLY, H. (1950): Coins of the Roman Empire in the British Museum vol. 5, Londres, British Museum, 560, no. 197 y 572, no. 273 (lám. 91-2).

31 BALDUS, H.R. (1996): «Uranius Antoninus of Emesa: A Roman Emperor from Palmyra's Neighbouring City and his Coinage», AAAS 42, 371-7 (no. 33).

32 Puede consultarse online en <http://www.omnesviae.org/> [Consultado el 20-04-2012].

33 IGLS 2760 = ILS 8958, cf. CIL VI 35556a y PARIBENI, R. (1900): «Di una iscrizione inedita di via labicana manzionante un re.straniero", $B C 28$, 33-43, sobre una inscripción en la 'propia Roma. Sobre la dinastía gobernante de Emesa, $c f$. SULLIVAN, R.D. (1978): "The Dynasty of 
REGI MAGNO /C(aio) IVLIO SOHAEMO / REGIS MAGNI SAM / SIGERAMI F(ilius) PHILO / CAESARI ET PHILO / [r] OHMAEO HONORA / T[o ornamentis] CONSVLARI / B[us ...] / PATRONO COLONIAE /[II]VIRO QVINQVEN$\mathrm{N}$ (ali) / L(ucius) VITELLIVS L(uci) F(ilio) FAB(ia tribu) SOSS[i]A[nus]

Young desdeña este testimonio, y pretende comparar la inscripción con otra que menciona a su padre, Sampsigéramo II, y a Germánico, hallada en Palmira, y cuya traducción es la siguiente ${ }^{34}$ :

[...] que es llamado Alejandro / [...] palmireno, porque ha hecho (?) / [...] previamente, y Germánico le ha enviado/ [...] de Maisan y la casa de Orabzes / [...] a excepción de $[\ldots] /[\ldots]$ Sampsigéramo, rey supremo / [...].

Como puede apreciarse de un simple vistazo, el argumento de Young no se sostiene. La inscripción de Palmira está escrita en el idioma local, y menciona al rey emeseno de pasada, entre otros personajes. La de Baalbek está en latín, servía de base a una estatua y trataba a Sohemo de "philorhomaios», "patrón de la colonia» y "duunviro quinquenal», alguien a quien los locales consideraban apropiado honrar de forma tan monumental. ${ }^{35}$ La colonia era, naturalmente, Berytus, puesto que Heliópolis no fue elevada a ese rango hasta época severiana.

El duunvirato quinquenal era la magistratura suprema de una colonia, equivalente a la censura. Sirva de comparativa que, al otro extremo del Mediterráneo, el casi coetáneo rey-cliente Juba II de Mauritania (c. 28 a. C.- 23 d. C.) fue patrón y duunviro quinquenal de Carthago Nova, donde se acuñó moneda a su nombre, así como duunviro de Gades (sede del famoso templo del Melqart-Hércules), hechos que Julio Mangas ha relacionado con la financiación de la Via Augusta, entonces en construcción ${ }^{36}$. Por analogía, ¿qué obra pública pudo financiar Sohemo en Baalbek/Heliópolis? Pues, evidentemente, el santuario donde se halló la susodicha inscripción.

Un texto pseudoprofético del s. VI aporta un importante testimonio que, de ser cierto, situaría el grueso de la construcción precisamente en época Julio-Claudia:

Emesa», ANRWII-8, 198-219.

34 CANTINEAU, J. (1931): «Textes Palmyréniens provenant de la fouille du temple de Bèl», Syria $12-2,116-41, n^{\circ} 18$ (139-41).

35 Sobre la naturaleza de la realeza clientelar y la filorromanidad, $c f$. BRAUND, D. (1984): Rome and the Friendly King: The Character of Client Kingship, Londres, Croon Helm.

36 CIL II 3417; AVIENO, Ora maritima, vv. 275-279; BELTRÁN MARTÍNEZ, A. (1980): «Iuba II y Ptolomeo de Mauritania IIviri quinquenales de Carthago Nova", Caesaragusuta 51-2, 133-141; MANGAS MANJARRÉS, J. (1988): «Iuba II de Mauritania, magistrado y patrono de ciudades hispanas», en Actas del Congreso Internacional "El Estrecho de Gibraltar» (Ceuta, noviembre 1987), t. I: Prehistoria e Historia de la Antigüedad, Madrid, UNED, 731-740. 
Antíoco, Tiberio y Cayo [Calígula] (...) levantarán los templos de Heliópolis y los altares del Líbano; y los santuarios de esa ciudad son más grandes y están mejor construidos que cualquier (otro) templo del mundo habitado ${ }^{37}$.

En este sentido, hay constancia expresa de que la inscripción y la estatua de Sohemo fueron coetáneas de la construcción del Gran Templo de Baalbek, como muestra un grafito escrito en un capitel del mismo antes de que se colocara el entablamento, que ha sido datado en el año $60^{38}$. Lo cual apunta con fuerza, aunque sólo sea de forma circunstancial, a que fue edificado por los reyes de Emesa. Como hemos visto, en el año 69 el culto solar ya estaba extendido entre los soldados de la III Gallica, estacionados en Raphanea (vide supra).

El único potentado oriental a quien también se trata de patronus coloniae Heliopolitanae en una inscripción latina de Baalbek fue el rey Agripa (no está claro si I ó II) ${ }^{39}$, que, sin embargo, no fue duunviro. Consta por la obra de Josefo que tanto Agripa I (41-44) como II (48-94) gastaron grandes sumas en embellecer Beirut, ciudad en cuyo territorio se hallaba Heliópolis/Baalbek ${ }^{40}$. El candidato más probable es Agripa II, puesto que fue coetáneo, pariente y amigo personal de Sohemo de Emesa; los dos acompañaron a Tito durante la Guerra Judaica, comandando tropas auxiliares, y estuvieron presentes en el Asedio de Jerusalén del año $70^{41}$. Agripa I recibió, al igual que Sohemo, los ornamenta consularia (de Claudio, en 41), y Agripa II los ornamenta praetoria (de Vespasiano, en 75$)^{42}$. Tales coincidencias parecen exceder la mera casualidad, pues recientes investigaciones han demostrado que las técnicas de construcción empleadas en los templos de Jerusalén y Baalbek fueron análogas ${ }^{43}$.

37 ALEXANDER, P.J. (1967): The Oracle of Baalbek. The Tiburtine Sybil in Greek Dress, Washington D.C., Dumbarton Oaks, 13, 25 y 43-4. La existencia de un templo helenístico bajo la actual construcción del s. I ya fue propuesta por GERKAN, A. von (1937): "Die Entwicklung des grossenTempels von Baalbek», y es respaldada por una inscripción, $c f$. MILLAR, F. (1987): “The Problem of Hellenistic Syria," en Kuhrt, A., y Sherwin-White, S. (eds.), Hellenism and the East. The Interaction of Greek and Non-Greek Civilizations from Syria to Central Asia after Alexander, Londres, Duckworth, 110.

38 IGLS 2733, fechado el 2 de loos de $371 \mathrm{AG}=2$ de agosto de $60 \mathrm{AD}$.

39 CIL III 14387 = ILS 8957 = IGLS V2759: [regi] / MAGNO AG[rip]PAE PIO PHILOCAE / SARE (sic) ET PHILOROMAHEO / PATRONO COL(oniae) / PVB(lice) FAC(tum).

40 JOSEFO, Ant. XIX, 335-337 y XX, 211-212. Berenice, hermana de Agripa II y amante de Tito, también se prodigó con Beirut, cf. GABBA, E. (1958): Iscrizioni greche e latine per lo studio della Bibbia, Turín, Marietti, 30.

41 JOSEFO, Ant. XX, 158, BJ II, 481-483 y 501, III, 68, y VII, 226; TÁCITO V, 1, 2. Cayo Julio Azizo, hermano y predecesor de Sohemo, estaba casado con Drusila, hija de Agripa I y hermana de Agripa II (JOSEFO, Ant. XX, 139); Iotape, hermana de Sohemo, estaba casada con Aristóbulo, hermano de Agripa I (JOSEFO, Ant. XVIII, 135).

42 DIÓN CASIO LX, 8, 2-3 y LXVI, 15, 3. Otro hermano de Agripa I, Herodes de Calcis, también recibió los ornamenta praetoria.

43 KROPP, A.J.M. y LOHMANN, D. (2011): “Master, look at the size of those stones! Look at the size of those buildings!' Analogies in Construction Techniques Between the Temples at Heliopolis 
Inadvertidamente, al mencionar la inscripción palmirena que hemos reproducido, Young añade un nuevo argumento a favor de la tesis de Ball: nada hay de extraordinario en que Sampsigéramo II fuera honrado en Palmira. Uno de los dioses solares palmirenos era YarhibollAglibelus, adorado en relación con el dios lunar Malakbelus ${ }^{44}$, de los cuales ha aparecido una inscripción de un tal Aurelio Heliodoro Adriano, datada en 235 y hallada precisamente en la Vigna Barberini del Palatino romano, donde se localizó el Heliogabalium $^{45}$. Dada la extensión del sincretismo en Siria, no es raro que Aglibelus fuera asimilado con una deidad de nombre tan sospechosamente similar como Elagabal, del cual Sapmsigéramo era sumo sacerdote, y que por ello se le honrara en Palmira. Sabemos además, por otra inscripción, que los palmirenos veneraban a Elagabal ${ }^{46}$.

Nos consta que el emperador contemporáneo de Sohemo y la construcción del Gran Templo de Baalbek, Nerón (54-68), veneró, a pesar de su ateísmo, a la Dea Syria, la Atargatis de Hierápolis Bambyce (junto al Eúfrates), que bien pudo sincretizarse con la Astarté-Venus heliopolitana, al ser diosa de la fecundidad ${ }^{47}$. La presunta tríada de Hierápolis (Hadad-Zeus, Atargatis-Afrodita y Semeion-Hermes) es idéntica a la heliopolitana (Baal-Júpiter, Astarté-Venus y Simius-Mercurio) ${ }^{48}$. Es significativo, a este respecto, que un veterano llamado Sexto Alio Julio dedicara un monumento a Hochmaea, profeta virgen de la Dea Syria, en Niha, en las proximidades de Baalbek ${ }^{49}$. Y que la diosa fuera también mencionada en una basa con una dedicatoria a Júpiter Heliopolitano en favor del emperador Gordiano III (240), hallada en la propia Roma ${ }^{50}$. Fue dedicada por un heliopolitano, Lucio Trebonio Sossiano, cuyo cognomen no podemos dejar de vincular con el de Lucio Vitelio Sossiano, que dedicó la estatua a Sohemo en el s. I.

Fergus Millar ha señalado que hay algo extraño en la política de Emesa, ya que no fue una ciudad-Estado normal: en el siglo I a. C. se habla del pueblo (ethnos) de los «emisenoi»,

(Baalbek) and Jerusalem», Levant 43-1, 38-50. Aunque la reconstrucción del Templo de Jerusalén se atribuye en exclusiva a Herodes el Grande, lo cierto es que las obras continuaron durante muchos años después de su muerte, casi hasta la misma destrucción de la ciudad y el complejo templario en el año 70.

44 KAIZER, T. (2002): The Religious Life of Palmyra. A Study of the Social Patterns of Worship in the Roman Period, Stuttgart Franz Steiner, 143-8 y 154-6.

45 CIL VI 710, cf. RÉVILLE, J. (1886): La religion à Rome sous les Sévères, París, Leroux, 50. STARCKY, (1976): «Stèle d'Élahagabal'», Melanges de I'Universite Saint-Joseph 49, 503-520.

47 SUETONIO, Ner. 56: "Religionum usque quaque contemptor, praeter unius Deae Syriae, hanc mox ita sprevit». APULEYO, Met. VIII, 25, 3, la califica de "omnipotens et omniparens Dea Syria».

48 Cf. HAJJAR, Y. (1977): La triade d'Heliopolis-Baalbek, 155; DRIJVERS, H.J.W. (1980): Cults and Beliefs at Edessa, Brill, Leiden, 76-121. SEYRIG, H. (1960): "Les dieux de Hierápolis», Syria 37, 233-252, estimaba que sólo se rendía culto a dos dioses en Hierápolis, Hadad y Atargatis, una idea recogida por BUTCHER; K. (2007): "Two Syrian Deities», Syria 84, 277-286.

49 IGLS 2928 y 2929. Aunque no se honrara a Hadad y a Atargatis por sus nombres propios, el sincretismo con los dioses heliopolitanos parece evidente.

50 CIL VI 423 = ILS 4287, cf. HAJJAR, Y. (1977): La triade d'Heliopolis-Baalbek, 371-375. 
cuyo phylarchos era Yámblico, pero no de ciudad alguna; en la epigrafía emesena del siglo II d. C. no hay mención alguna a la dinastía ni a las funciones habituales de una ciudad ${ }^{51}$. La única inscripción de la propia ciudad de Emesa que menciona a alguno de sus reyes corresponde a la tumba del sucesor de Sohemo, Cayo Julio Sampsigéramo (cuyo nombre denota su condición de rey-cliente), está en griego y data de 78-952. Sin embargo, en la región, fuera de la urbe, hay otras inscripciones del s. II que sí mencionan a miembros de la dinastía ${ }^{53}$.

En el s. VI, el cronista Juan Malalas mencionaba a un rey-sacerdote Sampsigéramo de Emesa en época de la invasión de Sapor I (c. 250), pero como sacerdote de Afrodita. Como ha demostrado Baldus, se trata del usurpador Lucio Julio Aurelio Sulpicio Uranio Antonino, que acuñó moneda mostrando el templo y la piedra de Elagabal, y el hecho de que rechazó a los persas es confirmado por una inscripción hallada en Qal'at al-Halwâys y datada en 252-3, que menciona a un héroe que obtuvo la victoria al invocar a Cronos. El cual fácilmente puede identificarse con Elagabal, ya que era común igualar al dios griego -y no sólo a Zeus-Júpiter- con Baal. Un pseudo-oráculo sibilino le trataba de «sacerdote enviado por el Sol», afirmando que la "Ciudad del Sol» se alzaría y que los fenicios castigarían a los persas: la identificación con Baalbek, la Heliópolis Fenicia, no puede ser más clara ${ }^{54}$.

En todo caso, el culto a Astarté parece haber tenido gran importancia en Baalbek, pues Constantino abolió la tradicional costumbre de la prostitución sagrada y demolió un templo de Venus para construir una iglesia en su lugar ${ }^{55}$. La Expositio Totius Mundi (s. IV) indicaba que la ciudad exportaba bellas jóvenes, cultistas de Venus, llamadas «libanítides» (es decir, las susodichas prostitutas) ${ }^{56}$.

Por supuesto, también tenemos documentado que el emperador Heliogábalo rindió culto a la Magna Mater, identificada con la Dea Syria, recibió el taurobolium, robó el busto de Cibeles para llevarlo a su Heliogabalium, y rindió culto a esta diosa, junto con la púnica Salambó, con su característico sincretismo (deidades, todas ellas, asimiladas con Afrodita-Venus) ${ }^{57}$.

51 MILLAR, F. (1993): The Roman Near East (31 BC - 337 AD), Cambridge, Harvard University Press, 300-303.

52 IGLS 2212 = CIG III 4511 = OGIS 604 = IGR III 1023. Cf. SULLIVAN R.D. (1978): «The Dynasty of Emesa», 218-9.

53 IGLS 2215, 2216, 2217, 2339, 2362, 2366, 2385, 2565 у 2707.

54 JUAN MALALAS XII, 26; IGLS 1799; cf. BALDUS, H.R. (1971): Uranius Antoninus..., 236252; POTTER, D.S. (2004): The Roman Empire at Bay, AD 180-395, Londres y Nueva York, Routledge, 249-250; POTTER, D.S. (1990): Prophecy and History in the Crisis of the Roman Empire, Oxford, Clarendon, 150-154 y 323.

55 SOZOMENO, Hist. Eccles. V, 10; ABUlfaraGiO, Hist. Compend. Dynast. 75.

56 Expositio Totius Mundi 30.

57 HA Vit. Hel. 7, 1-3. 
Desconocemos que aristócratas locales desempeńaban el sacerdocio de Zeus-Belos en Apamea y de Júpiter-Baal en Heliópolis/Baalbek, como era común en Oriente. Pero sí tenemos toda una dinastía de reyes-sacerdotes en Emesa, cuya vinculación con Heliópolis/Baalbek es harto sospechosa ${ }^{58}$.

\section{PISTAS ARQUEOLÓGICAS}

La gran mezquita de al-Nuri, la más probable localización del Templo de Heliogábalo en Emesa, fue construida sobre una basílica dedicada a San Juan Bautista ${ }^{59}$. Es interesante observar que la advocación es la misma que en Damasco, donde la basílica cristiana sustituyó al Templo de Júpiter Damasceno en el reinado de Teodosio.

Sin embargo, la mezquita no tiene suficientes dimensiones como para haber acogido un gran santuario pagano, en comparación con sus homólogos más cercanos: unos 100 x 80 metros, frente a los 480 x 300 del Monte Moriah, los 205 x 210 del Templo de Bel en Palmira y los 160 x 100 m del temenos ahora ocupado por la Gran Mezquita de Damasco. En comparación, el núcleo de la acrópolis de Baalbek tiene unas dimensiones de unos 200 x 200 metros (fig. 10). Solo el Gran Templo ya mide $90 \times 49 \mathrm{~m}$.

De igual modo, en la Gran Mezquita de Damasco, por ejemplo, se aprecia a la perfección la reutilización de materiales romanos y bizantinos, conservando un característico «sabor» tardorromano ${ }^{60}$. En la mezquita de Homs apenas hay unos cuántos capiteles corintios y restos de mosaico en el mirhab. Por tanto, en todo caso, estos restos quizá podrían corresponderse con la «sucursal» de Emesa, de dimensiones mucho más modestas, pero no con el Gran Templo de Elagabal propiamente dicho.

\section{NUEVAS EVIDENCIAS EN FUENTES TARDÍAS}

Además de lo anteriormente expuesto, hemos hallado nuevas evidencias que apoyarían la identificación del Heliogabalium con Baalbek, producto de una lectura cuidadosa de fuentes tardías.

58 Cf. SULLIVAN, R.D. (1977): «Priesthoods of the Eastern Dynastic Aristocracy», en SAHIN, S., SCHWERTHEIM, E., y WAGNER, J. (eds.), Studien zur Religion und Kultur Kleinasiens. Festsch. f. F.K. Dörner z. 65 Geburtstag (EPRO, 66), Leiden, 1977, 914-939; SULLIVAN, R.D. (1977): «The Dynasty of Emesa».

59 HERZFELD, E. (1921): «Baubeschreibung», en SOBERNHEIM, M. Die Inschriften der Moschee von Hims, Viena y Leipzig, Festschrift zu CF Lehmann-Haupts, 237-9.

60 STIERLIN, H. (2002): El Islam, desde Bagdad hasta Córdoba. Las edificaciones de los siglos VII al XIII, Colonia, Taschen, 45-60. 


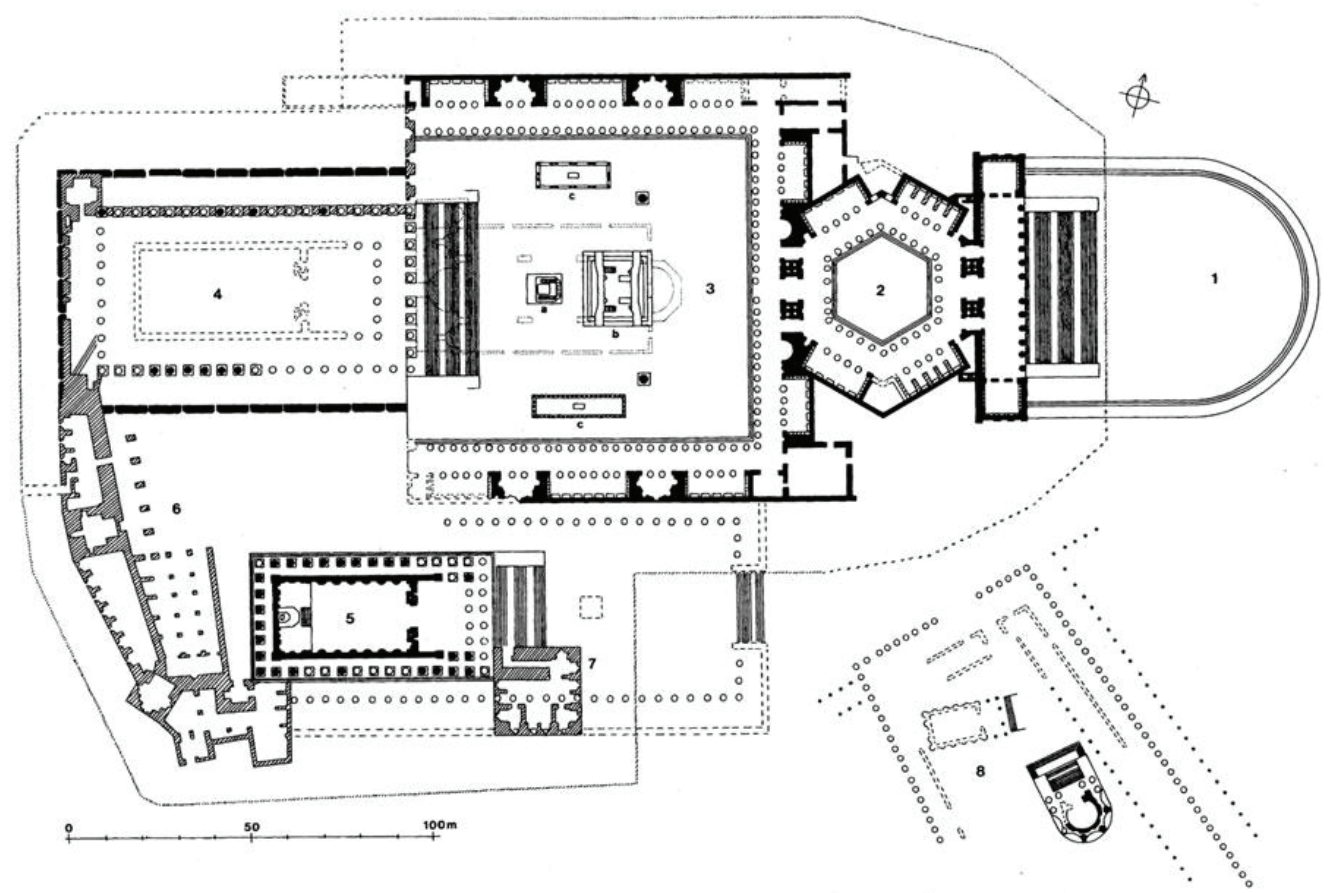

- Restos de época romana.

Fig. 13: plano de las ruinas de Baalbek (FREYBERGER, K.S. (2000): «Im Licht des Sonnengottes...», 98. ). Leyenda: 1, patio exterior; 2, patio hexagonal; 3, patio principal; 4, Gran Templo de Júpiter; 5, «Templo de Baco» ; 6, patio de la fortaleza árabe; 7, mazmorra medieval; 8, «Templo de Venus».

Avieno (s. IV), recorriendo de norte a sur el curso del Orontes, después de mencionar Apamea y Emesa, sin más detalle, se recreaba en el templo de Elagabal (mencionado el flammiconus, la piedra sagrada en forma de cono), el cual igualaba, de forma poética, con las cumbres de la cordillera de Líbano, situándolo junto al Orontes -pero no a orillas del mismo ${ }^{61}$. ¿Qué sentido tendría hacerlo si no se tratara del soberbio templo de Heliópolis/Baalbek, ciudad desde la cual son perfectamente visibles el Líbano y el Orontes, que nace en sus proximidades?

Según Juan Malalas (s. VI) y el Chronicon Paschale (s. VII), Teodosio el Grande convirtió el gran templo de Baal de la ciudad de Heliópolis en una iglesia cristiana, en la

${ }_{61}$ Descript. orb., vv. 1083-92: "Urbs mediis Apamea dehinc constitit in arvis, / et qua Phoebeam procul incunabula lucem / prima fovent, Emesae fastigia celsa renident. / Nam diffusa solo latus explicat; ac subit auras / turribus in coelum nitentibus: incola claris / cor studiis acuit, sed et amplius imbuit ordo: I Denique flammicomo devoti pectora soli / vitam agitaut. Libanus frondosa cacumina turget. / Et tamen his certant celsi fastigia Templi, / heic se indit iuxta tellurem glaucus Orontes». 
época en que proscribió el paganismo, y destruyó los demás templos de la ciudad ${ }^{62}$. Los restos de la basílica, en el patio principal del complejo, dan fe de ello.

Por supuesto, no fue Teodosio quien se presentó personalmente en Baalbek, sino un hombre de su máxima confianza, Materno Cinegio, prefecto del pretorio de Oriente y cónsul en $388^{63}$. En el año 385, el emperador Teodosio le había encargado hacer cumplir la prohibición de realizar sacrificios con propósitos adivinatorios ${ }^{64}$. Sabemos que Cinegio actuó en Siria en 388, extralimitándose en sus funciones, cerrando y destruyendo numerosos templos paganos con el apoyo y compañía del obispo Marcelo de Apamea $^{65}$, ciudad que se encuentra a cuatro jornadas de Emesa, y ocho de Baalbek.

Según Teodoreto de Ciro, Marcelo fue el primer obispo en aplicarse a destruir los santuarios paganos. Cuando llegó Cinegio a Apamea con sus tropas, centró su atención en un vasto y magnífico santuario de Júpiter, pero el edificio era tan sólido que su demolición parecía imposible. Cuando el obispo vio que el prefecto Cinegio temía emprender la demolición, le mandó a otras ciudades mientras él mismo se ocupaba del asunto. Un simple labriego le indicó el medio de abatir el templo: mientras el obispo echaba la siesta, perforaron tres de las durísimas columnas que rodeaban la cella, cada una de 16 cúbitos de circunferencia, apuntalándolas con madera de olivo, y la prendieron fuego. Tras un primer intento infructuoso, la milagrosa intercesión del obispo obró los resultados deseados. La primera columna que cayó, por su propio peso, arrastró consigo otras doce y el techo del templo. El estruendo fue tan tremendo que atrajo a toda la población de la ciudad, que elevó un himno. Teodoreto finalizaba su relato añadiendo que Marcelo destruyó otros templos y acabó ganándose la corona del martirio ${ }^{66}$.

Pero, ¿está tan claro como pudiera parecer cuál que el santuario destruido por Marcelo se hallaba en Apamea? Ni mucho menos.

Es bien sabido que el Templo de Zeus Belos en Apamea, era sede de un célebre oráculo, consultado por Septimio Severo y por Macrino, pero también el de Baalbek/

$\overline{62}$ JUAN MALALAS XIII, 37; Chron. Pas. Olimpiada 289a. Hay quien, basándose en los restos, retrasa su construcción al siglo V, $c f$. ESS, M. van, y WEBER, T. (coord; 1999): Baalbek, Im Bann..., 70-1. Sin embargo, creemos evidente que un edificio tarda cierto tiempo en construirse y puede estar sujeto a reformas posteriores.

PLRE 1, 235-6.

64 CTh XVI, 10, 9.

65 TEODORETO DE CIRO, Hist Eccl., V, 21.; Zósimo, NH IV, 37.

Ibidem. 
Heliópolis, consultado por Trajano ${ }^{67}{ }^{68}$. ¿Es razonable creer que dos oráculos de fama universal se hallaran separados sólo por $230 \mathrm{~km}$ de distancia entre sí? ¿ $\mathrm{O}$ es más lógico deducir que se trataba del mismo oráculo? En comparación, el oráculo de Delfos estaba a $140 \mathrm{~km}$ del de Oropos y a 320 del de Dodona, pero la densidad de población de la Grecia continental era bastante mayor que la de Siria. Y, desde luego, la fama del de Delfos eclipsaba a la de sus vecinos y competidores. No parece haber sido el caso de los tres oráculos sirios. En su Saturnalia, Macrobio menciona únicamente al Júpiter de Baalbek/ Heliópolis, sin hablar de sus homólogos de Emesa o Apamea. Cabe añadir que los restos del podio del considerado Templo de Zeus Belos en Apamea -aún por excavar- miden unos 40 x 20 metros (bastante más pequeño que el Partenón), unas dimensiones ridículas para lo usual en los grandes templos sirios. Aunque Jean-Charles Balty crea que las dimensiones de los bloques y la distancia y el desnivel con respecto al ágora de Apamea permiten hablar de una construcción tan amplia como el gran templo de Baalbek, los mezquinos restos arqueológicos no lo avalan en absoluto. Ni siquiera está claro que el oráculo que consultó Septimio Severo tenga algo que ver con Zeus Belos y la ciudad de Apamea.

Nos explicamos: aunque una lectura descuidada del citado pasaje de Teodoreto podría dar a entender que el templo destruido por Cinegio y Marcelo se hallaba en la propia ciudad de Apamea, Sozomeno, que narraba los mismos hechos ${ }^{69}$, indicaba el detalle de que el complejo en cuestión se hallaba no en la propia ciudad, sino en una falda montañosa (klima) en un lugar llamado Aulon, en el distrito de Apamea, y que el obispo Marcelo «había oído hablar» del mismo. De haberse hallado en la urbe o en sus proximidades, sería lógico pensar que obispo lo habría visto por sí mismo, y no que lo conociera únicamente de oídas. ¿Sería ilógico suponer que el oráculo consultado por Severo, se hallara en el distrito de Apamea, y no en la propia ciudad? Más aún si tenemos en cuenta

67 DIÓN CASIO LXXVIII, 8, 5-6 y 40, 3; REY-COQUAIS, J.P. (1973): «Inscriptions grecques d'Apamée», Annales Archéologiques Arabes Syriennes 23, 66-8; BALTY, J.C. (1981): «L’oracle d'Apamée", Antiquité Classique 50, 5-14; BALTY, J.C. (1988): "Apamea in Syria in the Second and Third Centuries AD», Journal of Roman Studies 78, 91-104; HAJJAR, Y. (1990): "Divinités oraculaires et rites divinatoires en Syrie et en Phénicie à l'époque gréco-romaine», Aufstieg und Niedergang der römischen Welt II, 18-4, 2236-2320; BALTY, J.C. (1991): "Apamée et la Syrie du Nord aux époques hellénistique et romaine», Revue du monde musulman et de la Méditerranée 62, 15-26; BALTY, J.C: (1997): «Le sanctuaire oraculaire de Zeus Bélos à Apamée», Topoi 7, 794-798. La célebre inscripción de Vaiso no menciona en absoluto Apamea, y de hecho ha sido atribuida repetidas veces a Sexto Vario Marcelo, que, aunque nativo de esa ciudad, se casó con la princesa emesena Julia Sohema y fue padre del emperador Heliogábalo.

68 MACROBIO, Sat. I, 23, cf. BEATRICE, P.F. (1997): «Das Orakel von Baalbek und die sogenannte Sibyllentheosophie», Römische Quartalschrift für christliche Altertumskunde und Kirchengeschichte 92-3/4, 177-189.

69 Hist. Eccl. VII, 15. Sin embargo, CHUVIN, P. (1999): Chronique des derniers païens. La disparition du paganisme dans l'Empire romain, du règne de Constantin à celui de Justinien, París, Fayard, 65-6, pensaba que se trataba de un suceso distinto, aunque sin argumentar su creencia, ya que el relato de Sozomeno deja claro que «templo de Apamea» era el de Aulon. 
su vinculación con la dinastía emesena, al casarse con Julia Domna, aconsejado por un horóscopo ${ }^{70}$. En cualquier caso, Marcelo asaltó el templo con un pequeńo ejército de soldados y gladiadores, quedándose al margen mientras observaba la destrucción. Pero cuando los paganos del lugar advirtieron que estaba solo, le prendieron y le quemaron vivo. Extrańamente, las autoridades locales desistieron de perseguir a sus asesinos.

También indicaba Sozomeno que, por la misma época, se destruyeron también los templos paganos de Petra y Areópolis (Ar-Rabba), en Arabia, y de "Heriópolis» (sic), en Fenicia ${ }^{71}$, es decir, Baalbek. Todos estos sitios nos han legado impresionantes ruinas, inexistentes en Emesa/Homs.

Según el importante testimonio de Teofrasto, Aulon era el nombre dado a la llanura de la Bekaa, entre las cordilleras del Líbano y el Antilíbano ${ }^{72}$. Es decir, a la región de Baalbek/Heliópolis. En cambio, no nos consta ese topónimo en las proximidades de Apamea. Sozomeno era nativo de Gaza y estudió en Beirut, por lo que debería conocer bien la zona y no separar ambos templos. Sin embargo, la confusión puede deberse a las múltiples fuentes de las que extrajo la información para su Historia Ecclesiastica, ya que los hechos ocurrieron mucho antes de su nacimiento. Lo mismo puede aducirse para el caso de Teodoreto que era obispo de Ciro, en el norte de Siria, explicando su confusión con respecto al martirio de Marcelo, ya que lo sitúa tiempo después de la destrucción del templo.

Lo más interesante es observar que el templo de Emesa pasa totalmente desapercibido en las fuentes sobre esta oleada antipagana, a pesar de su manifiesta importancia. Nuevamente, quizá porque el templo de Elagabal era el de Baalbek. Teodoreto sólo menciona Emesa una vez en su Historia Ecclesiastica, y no hace mención alguna al culto de Elagabal: indica sencillamente que los paganos locales profanaron una iglesia, convirtiéndola en un templo dedicado a Baco Andrógino, hecho que fue celebrado por Juliano el Apóstata (361-3), diciendo que habían prendido fuego a «las tumbas de los galileos» ${ }^{73}$. La ciudad era sede episcopal, y su comunidad cristiana lo suficientemente importante

$\overline{70} \quad$ Vit. Sev. 3, 9; Vit. Getae, 3, 1.

71 . Hay una inscripción que prueba la adscripción de Heliópolis/Baalbek a Fenicia (CIL III 202, de 213 d. C.). Pero también Emesa y Palmira eran situadas en Fenicia (HERODIANO V, 3, 2; ULPIANO, de censibus, pássim), y, de igual modo, el autor de las Etiópicas (s. IV), firmaba como Heliodoro, hijo de Teodosio, de la raza del Sol, natural de Emesa, en Fenicia (sic). AMIANO MARCELINO XIV, 8, 9, también situaba a Emesa en Fenicia, igualándola en categoría a Sidón, Beirut y Damasco, pero por debajo de Tiro; Malalas la adscribía a la provincia de Phoenicia Libanensis (JUAN MALALAS II, 22, XII, 26 y XIII, 37). Por supuesto, ni emesenos ni heliopolitanos eran «fenicios» en su actual sentido histórico y étnico. Sobre Heliodoro, $c f$. CHUVIN, P. (1999): Chronique des derniers païens..., 321-325.

72 TEOFRASTO, Hist. Plantar. IX, 7.

73 TEDORETO DE CIRO, Hist. Eccl. III, 7; JULIANO; Misopogon 357c. Ello a pesar de que se carteó con el obispo de la ciudad, Uranio (TEODORETO DE CIRO, Ep. 122 y 123). 
como para oponerse al nombramiento del obispo Eusebio hacia 340, acusado de practicar astrología ${ }^{74}$. Abanderado del arrianismo ${ }^{75}$, al parecer tuvo buenas relaciones con Constantino, acompañándole en alguna de sus campañas en Oriente ${ }^{76}$. No deja de ser llamativo, ya que este emperador atacó el culto a Venus en la vecina Heliópolis, como hemos visto.

Sozomeno informaba además que los paganos de Aulon armaron a hombres de Galilea y campesinos del Líbano en defensa de su templo. Un poco lejos se fueron a reclutar los presuntos apamenos. A menos, claro está, que se tratara de Baalbek, en cuyo caso no habrían hecho más que acudir a la gente local y sus vecinos del sur. Además, ello implica que la mayor parte de la población no era cristiana. Apamea y Emesa eran sedes episcopales.

Según Sozomeno, los paganos del lugar, molestos por la destrucción del templo, aprovecharon un momento en que el obispo quedó solo para quemarle vivo. Una violencia inaudita en las muy cristianas comunidades de Apamea o Emesa, pero que replica el martirio del actor cristiano Gelasino de Heliópolis, en época de Licinio ${ }^{77}$, la muerte del diácono Cirilo, cuyos asesinos devoraron su hígado después de que rompiera sus ídolos bajo Constantino ${ }^{78}$, así como un brutal pogrom anticristiano bajo el reinado de Juliano el Apóstata, que llegó al extremo de despedazar vivas a unas vírgenes, atrocidad que Sozomeno vinculaba a la prohibición de la prostitución sagrada bajo Constantino ${ }^{79}$. Imperando Valentiniano I, el prefecto de Egipto, Paladio - un pagano-, en connivencia con el nuevo patriarca arriano de Alejandría, Lucio, prendió a diecinueve presbíteros y diáconos ortodoxos y los deportó a la "Heliópolis Fenicia», ciudad de "placeres diabólicos» cuyos habitantes eran todos idólatras y no podían soportar escuchar el nombre de Cristo $(s i c)^{80}$.

Pero la clave para confirmar que el templo destruido por el obispo Marcelo de Apamea no fue sino el de Baalbek son sus columnas: según Teodoreto, medían 16 cúbitos romanos de circunferencia. Lo cual equivale a $7 \mathrm{~m}$, que es exactamente lo mismo que las columnas de Baalbek/Heliópolis, las más gigantescas del mundo romano. Desde luego, sin parangón en Siria en general y en Apamea en concreto.

74 SÓCRATES, Hist. Eccl. II, 9.

75 JERÓNIMO, Chron., ann. X Constantii.

76 Sobre este prelado, $c f$. WINN, R.E. (2011): Eusebius of Emesa: Church and Theology in the MidFourth Century, Washington D.C., The Catholic University of America Press.

77 JUAN MALALAS XII, 50. La Expositio Totius Mundi 32, confirma que Heliópolis era un centro teatral.

78 TEDORETO DE CIRO, Hist. Eccl. III, 7.

79 GREGORIO NACIANZENO, Contra Julianum I, 86-7; SOZOMENO, Hist. Eccl. V, 10.

80 TEDORETO DE CIRO, Hist. Eccl. IV, 19. 
Por tanto, creemos más que probable que la narración reproducida de oídas por Sozomeno y Teodoreto, trataba en realidad, de la destrucción del mayor y más importante santuario y oráculo del sur de Siria: el Elagabalium de Baalbek.

Podría argüirse, en contra de nuestro discurso, que el templo de Baalbek aún existía en el siglo VI: la Historia Ecclesiastica de Zacarías de Mitilene (c. 530), conservada únicamente en una crónica siria muy corrompida, afirma que el «templo de Salomón» en Heliópolis, fue destruido por el fuego causado por un rayo, datando el suceso en 525 y mezclándolo de forma confusa con otros prodigios, como el gran terremoto que asoló Antioquía en $526^{81}$. Idéntica historia es recogida en la Crónica de Miguel el Sirio $(\text { s. XII })^{82}$. Pero otro autor del s. VI que también sufrió una transmisión, Juan de Éfeso, narraba esta misma historia situándola en 555 (y cuatro ańos antes de un devastador terremoto y tsunami que en realidad ocurrió en 551). Señalaba que el templo de Balbek (sic) era tan espléndido que mantenía a los paganos en su error, e indicaba sus dimensiones exactas: 150 × 75 codos, es decir, 69 × 34 ' 5 metros, que son justo las medidas del mal llamado «Templo de Baco» ${ }^{83}$.

Una última fuente a considerar es el filósofo pagano del siglo VI Damascio, el cual comentaba en su Vida de Isidoro de Alejandría que visitó Baalbek/Heliópolis, donde afirmó haber visto meteoritos adorados como piedras sagradas y con capacidades oraculares (baetylia), vinculándolas al cercano Monte Líbano. Como bien recuerda Ball, Elagabal significa «dios de la montańa» (o «dios-montaña»). Es llamativo que Damascio se entrevistara con un tal Eusebio de Emesa, propietario de una de esas piedras, y dedicara esa obra a una tal Teodora, hija de Diógenes y descendiente de los antiguos reyes de Emesa $(s i c)^{84}$.

No tiene nada de extraño que Damascio, un pagano beligerante, viajara a Baalbek, pues fue uno de los últimos grandes baluartes del paganismo en Siria, al decir del obispo monofisita Juan de Éfeso. Según este autor, en 579, aprovechando una revuelta en Samaria, Tiberio II envió a sus tropas contra los paganos de Baalbek, temiendo que se impusieran por la fuerza a la población cristiana, torturándolos para que delataran a sus cómplices, decapitándolos, crucificándolos y expropiando sus bienes, dando inicio a una purga antipagana en todo Oriente ${ }^{85}$.

$\overline{81}$ ZACARIAS DE MITILENE, Hist. Eccl. VIII, 4.

82 MIGUEL EL SIRIO, Chron. IX, 16.

83 NAU, F. (1897): «L'histoire ecclesiastique de Jean d'Asie», Revue de l'Orient chrétien 2, 490-1.

84 FOCIO, Biblio. 242, cf. LAMMENS, H. (1920): «Le cult des bétyles et les processions religieuses chez les Arabes préislamites", Bulletin de l'Institut d'Archeologie Orientale du Caire 17, 39-101.

85 JUAN DE ÉFESO, Hist. Eccl. III, 27-8, cf. KAEGI, W. (1966): «The Fifth-Century Twilight of Byzantine Paganism», Classica et Medievalia 27, 243-275, y CHUVIN, P. (2009): Chronique des derniers païens..., 145 y 147. 


\section{CONCLUSIONES}

La tesis de Ball resuelve el problema de la ausencia de restos arqueológicos de un gran templo en Emesa y el enigma planteado por Baalbek, el mayor y más suntuoso complejo templario de Siria, del que, sin embargo, apenas sabemos nada.

Es bien sabido que el argumento ex silentio jamás es definitivo en arqueología. Pero es igualmente obvio que este hecho no puede servir para ignorar la ausencia de restos arqueológicos de relevancia en Homs, aun a falta de serias excavaciones, en especial en la mezquita de Al-Nuri.

Habiendo rastreado por nuestra cuenta diversas fuentes literarias, y a falta de un análisis más exhaustivo, parecen ceñirse a su hipótesis, apuntando con fuerza a una estrecha relación de Baalbek/Heliópolis con los reyes emesenos y el culto de Elagabal.

En consecuencia, debido a su coherencia explicativa y congruencia, creemos que debe aceptarse como válida la hipótesis de Warwick Ball, por lo menos hasta que aparezcan nuevas evidencias que despejen incógnitas sobre los templos de Emesa y Baalbek, confirmando o desmintiendo la identificación propuesta. 